\title{
LIPID PROFILE IN RDS GROUP AND NON-RDS GROUP: A COMPARISON STUDY
}

Sanjay Duruvasan ${ }^{1}$, Mohamed Haseen Basha ${ }^{2}$, Gururaj Somala Naik ${ }^{3}$, Chandrashekar Goulit, Ashoka Anandappa ${ }^{5}$, Latha Gowdru Shamanur, Nijalingappa Kenchappa Kalappanavar ${ }^{7}$, Prasad Budihal Shivana Gowda ${ }^{8}$

${ }_{1}^{1}$ Associate Professor, Department of Paediatrics, SSIMS \& RC, Davangere.

${ }^{2}$ Assistant Professor, Almareefa College of Medicine, Riyad, Saudi Arabia.

${ }^{3}$ Senior Resident, Department of Paediatrics, SSIMS \& RC, Davangere.

${ }^{4}$ Associate Professor, Department of Paediatrics, SSIMS \& RC, Davangere.

${ }^{5}$ Associate Professor, Department of Paediatrics, JJMMC, Davangere.

${ }^{6}$ Professor, Department of Paediatrics, SSIMS \& RC, Davangere.

7 Professor, Department of Paediatrics, SSIMS \& RC, Davangere.

${ }^{8}$ Professor, Department of Paediatrics, SSIMS \& RC, Davangere.

\section{ABSTRACT}

Lipid metabolism has an important role in fetal development during the late stage of gestation including growth and fat accretion in utero, increasing amniotic fluid lecithin levels with maturation of pulmonary function and changes in the levels of minor phospholipids in amniotic fluid.

\section{OBJECTIVE}

The aim of this study was to compare cord lipid profiles of preterm infants with Respiratory Distress Syndrome (RDS) and a control group without RDS.

\section{METHOD}

The study groups consisted of 56 preterm infants with gestational ages ranging from 28 to 36 weeks and birth weights ranging from 0.8 to $2.26 \mathrm{~kg}$. Of these infants, 29 developed RDS and 27 infants served as controls. Cord blood lipid profile was done in both the groups and compared.

\section{RESULT}

Total cholesterol, high-density and Low-Density Lipoproteins (LDL) cholesterols levels were lower in infants with RDS than in controls $(\mathrm{P}<0.05)$.

\section{CONCLUSION}

RDS is accompanied with lipid alteration in infants.

\section{KEYWORDS}

Serum Lipid Levels, Respiratory Distress Syndrome, Preterm Infants.

HOW TO CITE THIS ARTICLE: Duruvasan S, Basha MH, Naik GS et al. "Lipid profile in RDS group and non-RDS group: a comparison study." Journal of Evolution of Medical and Dental Sciences 2015; Vol. 4, Issue 104, December 28; Page: 16935-16938,

DOI: $10.14260 /$ jemds/2015/2552

\section{INTRODUCTION}

Cholesterol was found to represent over $50 \%$ of the neutral lipid of both the total surfactant and the lamellar body fractions and de novo synthesis of cholesterol from acetate accounted for only $1 \%$ of the surfactant cholesterol, the remainder being derived from exogenous cholesterol supplied as serum lipoproteins. ${ }^{1-6}$ The function of cholesterol in surfactant has not been established; however, it is believed to facilitate spreading of dipalmitoyl phosphatidylcholine at the air-liquid interface in the lung, lowering surface tension.1,2 Hass et al. ${ }^{3}$ suggested that lung cholesterol metabolism might be subject to regulation by both Low-Density Lipoprotein (LDL) and High-Density Lipoprotein (HDL). The infants who subsequently developed respiratory distress had significantly

Financial or Other, Competing Interest: None.

Submission 30-11-2015, Peer Review 01-12-2015,

Acceptance 18-12-2015, Published 26-12-2015.

Corresponding Author:

Dr. Sanjay Duruvasan,

1665/42, Nandanam,

SS Layout, A Block,

Davangere.

E-mail: drsanjay78@yahoo.com

DOI:10.14260/jemds/2015/2552 lower lipoprotein levels than the levels in normal new-borns and in preterm infants without respiratory distress after delivery. ${ }^{6}$

Additionally several factors significantly affected cord serum levels, especially gestational age and birth weight. 4,5 Lipid metabolism has an important role in fetal development during the late stage of gestation including growth and fat accretion in utero, transport of cholesterol to the fetal adrenal for hormone synthesis, increasing amniotic fluid lecithin levels with maturation of pulmonary function and changes in the levels of minor phospholipids in amniotic fluid. A deficiency or reduced transport of essential and/or long-chain polyunsaturated fatty acids, which resulted in lipid alterations could inhibit normal fetal growth and maturation, one effect of which would be delayed development of the fetal lungs, which could lead to the Respiratory Distress Syndrome (RDS) postnataly.

\section{MATERIALS AND METHODS}

From January 2015 to September 2015, a total of 414 neonates were admitted to the neonatal intensive care unit. The inclusion criterion at admission was preterm infant whose gestational age is between 28 and 36 weeks. The exclusion criterion at admission were large or gestational age, asphyxiated at birth and major congenital anomalies. 
Mothers whose pregnancies were complicated by hypertension and pre-eclampsia or with maternal history of endocrine disorders such as diabetes, hypercholesterolaemia, thyroid or adrenal problems or who had received alcohol were excluded. Infant whose mother was taking drugs affecting the lipid metabolites, such as steroid (Except for fetal lung maturation) and Ritodrine were excluded from the study. We aimed to minimize the effect of the intrauterine environment on lipid profile. Total 56 infants were included in the study. Informed consent was obtained from the parents before enrolment and the project was approved by Hospital Committee for Research on Human Subjects. The presence of antenatal corticosteroid administration, gender, gestational age, birth weight, height, ponderal index, length, mode delivery, Apgar scores and mode of delivery were recorded for each infant. The infant's gestational age at birth was calculated from the date of the last menstrual period and confirmed by ultrasonography. After an infant met admission criteria, the diagnosis of RDS was established by meeting the following criteria: physical examination notable for chest wall retractions and cyanosis on room air, compatible x-ray demonstrating diffuse alveolar atelectasis, arterial blood gas documentation of metabolic acidosis, hypoxaemia and hypercapnia.

Control infants met all admission requirements, but did not develop respiratory distress. RDS was further graded by down scoring into mild.(1-3) moderate. ${ }^{(4-6)}$ and severe.(7-10) Cord blood samples were obtained from umbilical vein immediately after delivery and allowed to clot at room temperature for 20 min. Serum was separated by centrifugation $(20 \mathrm{~min}, 2500$ $\mathrm{rpm}$ ) and kept at analysis was done. Serum triglycerides, total, HDL, LDL and VLDL cholesterol concentrations were measured using standard enzymatic methods with a fully automated analyzer. Results are presented as mean and SD. Unpaired ' $t$ ' test was used to compare the means of two groups. One way ANOVA was for multiple group comparisons. A P value of 0.05 or less was considered for statistical significance. SPSS (version 17) software was used for data analysis.

\section{RESULTS}

The study groups consisted of 56 preterm infants with gestational ages ranging from 28 to 36 weeks and birth weights ranging from $800 \mathrm{gm}$ to $2200 \mathrm{~g}$. Of these infants, 29 developed RDS and 27 infants served as controls. Mean total, HDL, LDL, VLDL cholesterol and triglyceride levels were significantly lower in all gestational age groups of the infants with RDS than in the controls $(\mathrm{P}<0.05)$.

\begin{tabular}{|c|c|c|c|c|c|c|c|}
\hline \multirow{2}{*}{ Variables } & \multicolumn{2}{|c|}{ RDS } & \multicolumn{2}{c|}{ Non-RDS } & \multicolumn{3}{c|}{ RDS v/s Non-RDS } \\
\cline { 2 - 8 } & Mean & SD & Mean & SD & Mean Diff & t & P \\
\hline Tg & 42.32 & 21.42 & 72.00 & 38.73 & 29.68 & 3.58 & $0.001^{*}$ \\
\hline LDL & 44.74 & 17.88 & 52.99 & 19.40 & 8.24 & 1.66 & $0.10, \mathrm{~ns}$ \\
\hline VLDL & 21.09 & 12.80 & 29.97 & 13.01 & 8.88 & 2.57 & $0.013^{*}$ \\
\hline HDL & 30.92 & 6.48 & 39.14 & 11.71 & 8.23 & 3.29 & $0.002^{*}$ \\
\hline TC & 114.01 & 31.43 & 130.46 & 24.19 & 16.45 & 2.18 & $0.033^{*}$ \\
\hline \multicolumn{6}{|c|}{ Lipid profile in RDS and Non-RDS } \\
\hline
\end{tabular}

Unpaired ' $\mathrm{t}$ ' test

$* \mathrm{P}<0.05, \mathrm{~S}$

$\mathrm{P}>0.05$, not sig

\begin{tabular}{|c|c|c|c|c|c|c|c|}
\hline \multirow{2}{*}{ Lipid } & \multirow{2}{*}{ GA (Wks.) } & \multicolumn{2}{|c|}{ RDS } & \multicolumn{2}{|c|}{ Non-RDS } & \multicolumn{2}{|c|}{ Overall } \\
\hline & & Mean & SD & Mean & SD & Mean & SD \\
\hline \multirow{7}{*}{$\mathrm{Tg}$} & 28 & 16.9 & 7.4 & 32.0 & 4.1 & 22.4 & 9.8 \\
\hline & 30 & 28.0 & & 89.5 & 64.0 & 80.7 & 62.8 \\
\hline & 32 & 51.3 & 15.1 & 69.4 & 7.6 & 59.3 & 15.2 \\
\hline & 34 & 46.9 & 20.2 & 67.6 & 3.6 & 56.0 & 18.3 \\
\hline & 36 & 65.7 & 8.1 & 106.7 & 54.9 & 86.2 & 41.7 \\
\hline & $\mathrm{F}$ & 7.91 & - & 2.45 & - & 6.81 & - \\
\hline & $\mathrm{P}$ & $0.00^{* *}$ & - & $0.08, \mathrm{~ns}$ & - & $0.00^{* *}$ & - \\
\hline \multirow{7}{*}{ LDL } & 28 & 25.3 & 3.8 & 31.8 & 1.3 & 27.6 & 4.4 \\
\hline & 30 & 34.0 & & 36.8 & 7.9 & 36.4 & 7.3 \\
\hline & 32 & 55.1 & 10.4 & 68.1 & 19.6 & 60.8 & 16.0 \\
\hline & 34 & 55.6 & 13.4 & 63.0 & 12.2 & 58.8 & 13.0 \\
\hline & 36 & 30.0 & 23.4 & 55.2 & 17.3 & 42.6 & 23.0 \\
\hline & $\mathrm{F}$ & 9.35 & - & 7.59 & - & 13.54 & - \\
\hline & $\mathrm{P}$ & $0.0^{* *}$ & - & $0.001^{*}$ & - & $0.00^{* *}$ & - \\
\hline \multirow{7}{*}{ VLDL } & 28 & 4.0 & 1.7 & 9.9 & 1.7 & 6.2 & 3.4 \\
\hline & 30 & 5.0 & & 34.0 & 12.4 & 29.8 & 15.7 \\
\hline & 32 & 27.9 & 8.1 & 25.5 & 10.5 & 26.8 & 9.0 \\
\hline & 34 & 29.0 & 8.9 & 38.9 & 7.0 & 33.3 & 9.3 \\
\hline & 36 & 22.0 & 8.0 & 38.3 & 5.7 & 30.2 & 10.9 \\
\hline & $\mathrm{F}$ & 15.12 & - & 8.01 & - & 14.59 & - \\
\hline & $\mathrm{P}$ & $0.00^{* *}$ & - & $0.00^{* *}$ & - & $0.00^{* *}$ & - \\
\hline \multirow{7}{*}{ HDL } & 28 & 25.1 & 2.8 & 33.0 & 3.8 & 27.9 & 5.0 \\
\hline & 30 & 30.0 & & 30.4 & 3.8 & 30.4 & 3.4 \\
\hline & 32 & 32.2 & 6.4 & 34.1 & 8.3 & 33.0 & 7.1 \\
\hline & 34 & 34.6 & 5.6 & 52.6 & 11.6 & 42.5 & 12.5 \\
\hline & 36 & 30.0 & 9.2 & 45.2 & 5.1 & 37.6 & 10.6 \\
\hline & $\mathrm{F}$ & 2.9 & - & 8.63 & - & 5.48 & - \\
\hline & $\mathrm{P}$ & $0.04^{*}$ & - & $0.00^{* *}$ & - & $0.001^{*}$ & - \\
\hline \multirow{7}{*}{ TC } & 28 & 92.1 & 21.0 & 102.8 & 6.7 & 96.0 & 17.5 \\
\hline & 30 & 95.0 & . & 117.5 & 17.5 & 114.3 & 18.1 \\
\hline & 32 & 126.4 & 20.0 & 143.9 & 12.4 & 134.1 & 18.8 \\
\hline & 34 & 128.1 & 29.9 & 131.9 & 25.3 & 129.8 & 27.1 \\
\hline & 36 & 91.7 & 56.1 & 158.7 & 23.2 & 125.2 & 53.1 \\
\hline & $\mathrm{F}$ & 2.62 & - & 5.66 & - & 4.02 & - \\
\hline & $\mathrm{P}$ & $0.06, \mathrm{~ns}$ & - & 0.003* & - & $0.007^{*}$ & - \\
\hline \multicolumn{8}{|c|}{ One Way ANOVA, $* \mathrm{P}<0.05, \mathrm{~S}, * * \mathrm{P}<0.001, \mathrm{HS}$} \\
\hline
\end{tabular}




\begin{tabular}{|c|c|c|c|}
\hline Lipid & $\begin{array}{c}\text { Severity of } \\
\text { Distress }\end{array}$ & Mean & SD \\
\hline \multirow{5}{*}{ Tg } & Mild & 63.3 & 4.9 \\
\hline & Moderate & 39.3 & 17.3 \\
\hline & Severe & 22.3 & 15.2 \\
\hline & $\mathrm{F}$ & 22.12 & - \\
\hline & $\mathrm{P}$ & $0.00^{* *}$ & - \\
\hline \multirow{5}{*}{ LDL } & Mild & 62.6 & 3.8 \\
\hline & Moderate & 38.9 & 16.0 \\
\hline & Severe & 31.3 & 13.1 \\
\hline & $\mathrm{F}$ & 17.70 & - \\
\hline & $\mathrm{P}$ & $0.00^{* *}$ & - \\
\hline \multirow{5}{*}{ VLDL } & Mild & 34.3 & 3.4 \\
\hline & Moderate & 18.1 & 9.3 \\
\hline & Severe & 9.6 & 9.2 \\
\hline & $\mathrm{F}$ & 25.104 & - \\
\hline & $\mathrm{P}$ & $0.00^{* *}$ & - \\
\hline \multirow{5}{*}{ HDL } & Mild & 36.9 & 2.9 \\
\hline & Moderate & 30.5 & 5.7 \\
\hline & Severe & 24.7 & 3.3 \\
\hline & $\mathrm{F}$ & 20.06 & - \\
\hline & $\mathrm{P}$ & $0.00^{* *}$ & - \\
\hline \multirow{5}{*}{ TC } & Mild & 145.7 & 6.5 \\
\hline & Moderate & 103.3 & 30.4 \\
\hline & Severe & 90.7 & 19.0 \\
\hline & $\mathrm{F}$ & 18.02 & - \\
\hline & $\mathrm{P}$ & $0.00^{* *}$ & - \\
\hline \multicolumn{4}{|c|}{ One Way ANOVA } \\
\hline \multicolumn{2}{|c|}{$* \mathrm{P}<0.05, \mathrm{~S}$} & & \\
\hline \multicolumn{2}{|c|}{$* * \mathrm{P}<0.001, \mathrm{HS}$} & & \\
\hline
\end{tabular}

\begin{tabular}{|c|c|c|c|}
\hline Lipid & Neonata Wt. (Kg) & Mean & SD \\
\hline \multirow{6}{*}{$\mathrm{Tg}$} & $<1.0$ & 16.7 & 6.4 \\
\hline & $1.0-1.5$ & 43.3 & 20.4 \\
\hline & $1.5-2.0$ & 46.2 & 21.9 \\
\hline & $2.0-2.5$ & 60.0 & - \\
\hline & $\mathrm{F}$ & 1.99 & - \\
\hline & $P$ & $0.14, \mathrm{~ns}$ & - \\
\hline \multirow{6}{*}{ LDL } & $<1.0$ & 24.0 & 5.3 \\
\hline & $1.0-1.5$ & 48.5 & 15.9 \\
\hline & $1.5-2.0$ & 48.3 & 17.4 \\
\hline & $2.0-2.5$ & 15.0 & - \\
\hline & $\mathrm{F}$ & 3.26 & - \\
\hline & $P$ & $0.03^{*}$ & - \\
\hline \multirow{6}{*}{ VLDL } & $<1.0$ & 4.1 & 2.5 \\
\hline & $1.0-1.5$ & 22.3 & 14.2 \\
\hline & $1.5-2.0$ & 24.6 & 9.9 \\
\hline & $2.0-2.5$ & 14.0 & - \\
\hline & $\mathrm{F}$ & 2.57 & - \\
\hline & $P$ & $0.08, \mathrm{~ns}$ & - \\
\hline \multirow{6}{*}{ HDL } & $<1.0$ & 23.5 & 2.7 \\
\hline & $1.0-1.5$ & 30.4 & 4.7 \\
\hline & $1.5-2.0$ & 34.2 & 6.6 \\
\hline & $2.0-2.5$ & 20.0 & - \\
\hline & $\mathrm{F}$ & 4.66 & - \\
\hline & $\mathrm{P}$ & $0.01^{*}$ & - \\
\hline \multirow{6}{*}{ TC } & $<1.0$ & 80.0 & 10.0 \\
\hline & $1.0-1.5$ & 124.2 & 24.7 \\
\hline & $1.5-2.0$ & 117.5 & 29.9 \\
\hline & $2.0-2.5$ & 41.0 & - \\
\hline & $\mathrm{F}$ & 4.95 & - \\
\hline & $P$ & $0.008^{*}$ & - \\
\hline \multicolumn{4}{|c|}{ One Way ANOVA } \\
\hline \multicolumn{2}{|c|}{$* \mathrm{P}<0.05, \mathrm{~S}$} & & \\
\hline
\end{tabular}
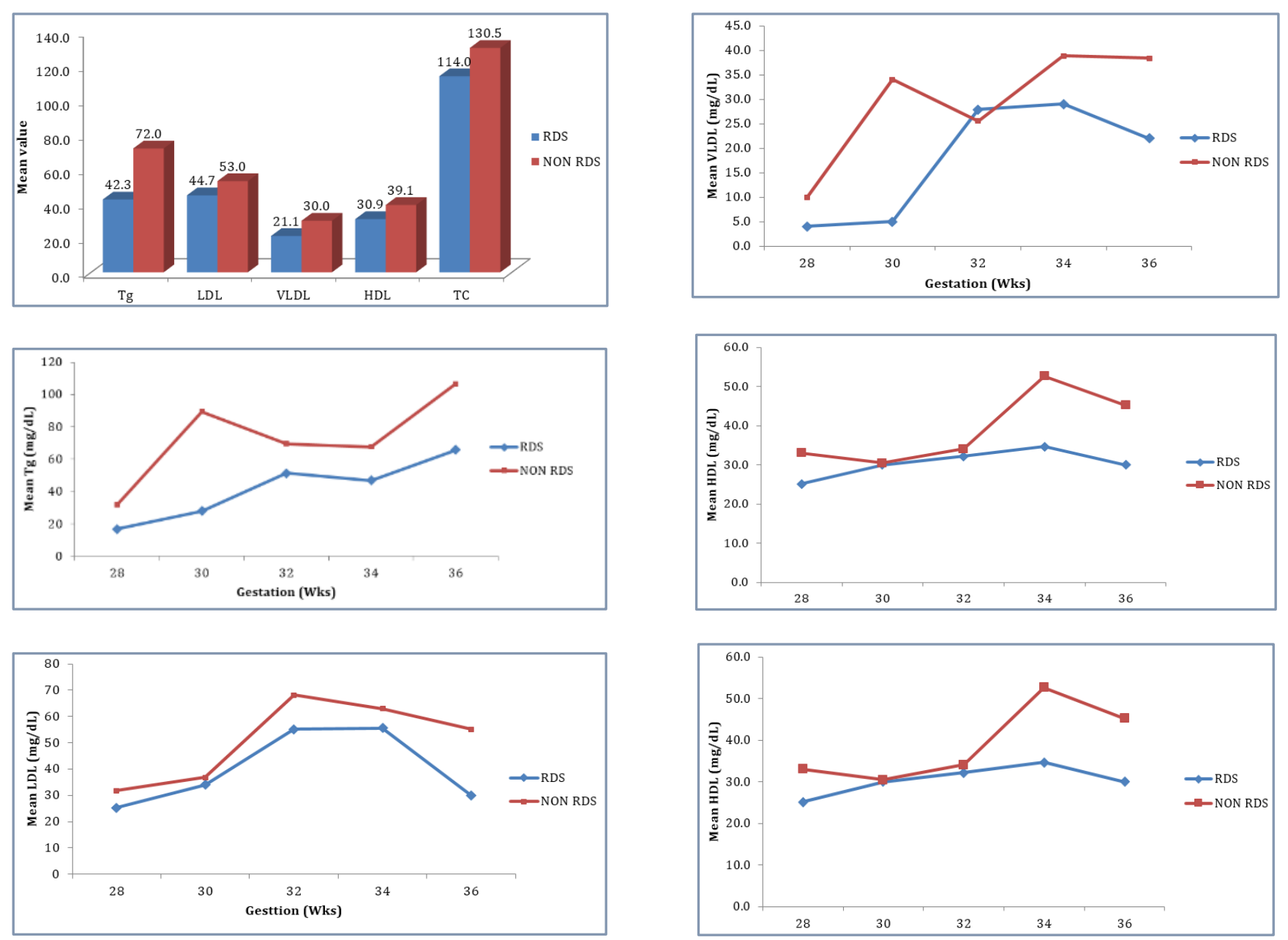


\section{DISCUSSION}

Factors during pregnancy and delivery as well as certain diseases can influence fetal and neonatal lipid metabolism.6,7,8 In agreement with our findings, Lane et al..$^{5}$ found that preterm infants developing respiratory distress post-nataly had significantly lower cord serum lipid levels than those of normal term infants or preterm infants free of respiratory distress. Significantly lower cord serum lipid levels are evidence of reduced essential fatty acids and long-chain polyunsaturated fatty acid supply, which could inhibit fetal growth in utero delaying maturation of fetal lungs. WojcickaJagodzinska et al. ${ }^{9}$ speculated that a reduction in the cholesterol concentrations of amniotic fluid of hypertensive mothers in whose children the respiratory distress syndrome developed, might have a prognostic significance in the prediction of respiratory distress in early neonatal period.

Compared with the values of non-RDS infants, lower levels of cholesterol and HDL cholesterol found in infants with RDS indicated a limited ability to metabolize VLDL, probably related to lipoprotein lipase impairment. Reduced levels of serum HDL cholesterol found in infants with RDS and in their mothers suggest that it may have an important role on regulating surfactant synthesis. Voyno Yasenetskaya et al.10 demonstrated that both LDL and HDL cholesterol stimulate primary cultures of type II cells to secrete phosphatidylcholine, the major phospholipid component of pulmonary surfactant.

In conclusion, RDS is accompanied with lipid alteration in the infants. We suggest that cord or serum lipid levels might be with the potential to detect those infants at risk for RDS that develops post-natally.

\section{REFERENCES}

1. Hass MA, Longmore WJ. Surfactant cholesterol metabolism of the isolated perfused rat lung. Biochim Biophys Acta 1979;573:166-174.
2. King RJ. The surfactant system of the lung. Journal of Perinatology 1974;33:2238-2247.

3. Hass MA, Longmore WJ. Regulation of lung surfactant cholesterol metabolism by serum lipoproteins. Lipids 1980;15:401-446.

4. Hardell LI. Serum lipids and lipoproteins at birth based on study of 2815 new-born infants. II. Relation between materno-fetal factors and concentration of triglycerides and cholesterol. Acta Paediatr Scand 1981;285:11-20.

5. Lane DM, McConathy WJ. Factors affecting the lipid and apolipoprotein levels of cord sera. Pediatr Res 1983;17:83-91.

6. Lane DM, McConathy WJ, McCaffree MA, et al. Cord serum lipid and apolipoprotein levels in preterm infants with the neonatal respiratory distress syndrome. J Matern Fetal Neonatal Med 2002;11:118-125.

7. Merzouk H, Madani S, Prost J, Loukidi B, MeghelliBouchenak M, Belleville J. Changes in serum lipid and lipoprotein concentrations and compositions at birth and after 1 month of life in macrosomic infants of insulindependent diabetic mothers. Eur J Pediatr 1999;158:750756.

8. Merzouk H, Meghelli-Bouchenak M, el-Korso N, et al. Low birth weight at term impairs cord serum lipoprotein compositions and concentrations. Eur J Pediatr 1998;157:321-326.

9. Wojcicka-Jagodzinska J, Romejko E, Smolarczyk R, et al. Respiratory distress in new-borns born to hypertensive mothers and protein, lipid and renal maturity indices and enzymatic activity in the amniotic fluid. Ginekol Pol 1989;60:485-488.

10. Voyno-Yasenetskaya TA, Dobbs LG, Erickson SK, et al. Lowdensity lipoprotein- and high-density lipoproteinmediated signal transduction and exocytosis in alveolar type II cells. Proc Natl Acad Sci USA 1993;90:4256-4260. 